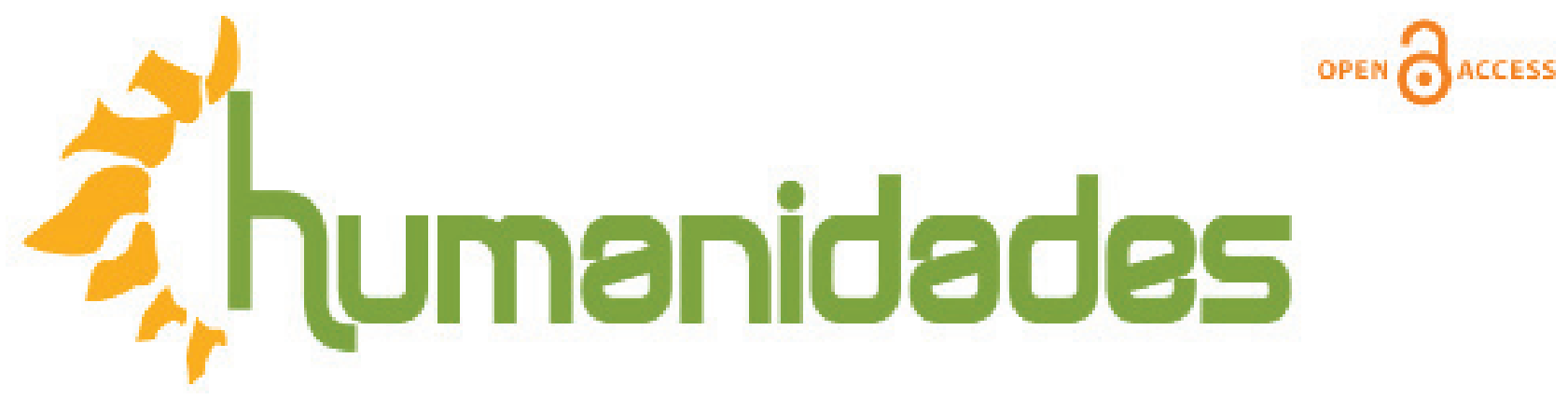

Revista de la Escuela de Estudios Generales, Universidad de Costa Rica

Enero-julio, 2019 •Volumen 9, número 1 • EISSN 2215-3934•pp. 1- 23

Recibido: 1-Agosto-2018 Aceptado: 1-noviembre-2018

\title{
De la otredad autóctona a la otredad idealizada: una comparación iconográfica y poscolonial de la obra (selección de óleos) de Enrique Echandi Montero y Tomás Povedano de Arcos
}

DOI: https://doi.org/10.15517/h.v9i1.35340

\section{Andrea Calvo Díaz}

Licenciada en artes. Docente de la Universidad de Costa Rica y de la Universidad Nacional, Costa Rica.

Correo electrónico: andrea.calvo_d@ucr.ac.cr

Todos los derechos reservados. Universidad de Costa Rica. Esta revista se encuentra licenciada con Creative Commons. Reconocimiento-NoComercial-SinObraDerivada 3.0 Costa Rica. Correo electrónico: humanidades@ucr.ac.cr/ Sitio web: http: //revistas.ucr.ac.cr/index.php/ humanidades 


\title{
De la otredad autóctona a la otredad idealizada: una comparación iconográfica y poscolonial de la obra (selección de óleos) de Enrique Echandi Montero y Tomás Povedano de Arcos
}

\section{Resumen}

El presente artículo tiene por objetivo problematizar los conceptos de otredad autóctona y otredad idealizada implementadosen las artes visuales costarricense a mediados del siglo XIX e inicios del siglo XX, desde una perspectiva iconográfica y poscolonial. Se entiende por otredad autóctona a la representación originaria costarricense y por otredad imaginada a la concepción europea cimentada en la pintura académica costarricense. Para el estudio se confronta la obra de Enrique Echandi (artista costarricense) con la pintura de Tomás Povedano de Arcos (artista europeo). Al final del texto se realiza una reflexión poscolonial respecto al conflicto Echandi vs. Povedano.

\section{From the Autochthonous Otherness to the Idealized Otherness: an Iconographic and Postcolonial Comparison of the Work (Selection of Oil Paintings) by Enrique Echandi Montero and Tomás Povedano de Arcos}

\begin{abstract}
This article aims to problematize the concepts of autochthonous otherness and idealized otherness implemented in the Costa Rican visual arts, of the late XIX and early XX, from an iconographic and poscolonial perspective. Autochthonous otherness is understood as the native/ original Costa Rican representation and imagined otherness as the European conception rooted in Costa Rican arts. For visual arts, this study, the work of Enrique Echandi a (Costa Rican artist) is confronted with the paintings of Thomas Povedano de Arcos a (European artist). At the end a poscolonial reflection is done on the conflict Echandi vs. Povedano
\end{abstract}

Palabras clave: otredad, iconografía, poscolonialdad, Enrique Echandi, Tomás Povedano
Keywords:

otherness, iconography, poscoloniality, Enrique Echandi, Tomás Povedano 


\section{Introducción}

A mediados del siglo XIX y principios del siglo XX surgió en Costa Rica un auge artístico y cultural; no obstante, este proceso fue marcado por la preferencia del discurso visual europeo. De este modo, se originó un conflicto nacional en las artes visuales costarricenses, pues se apoyó la iniciativa de acopiar la cultura Occidentalen lugar de la representación autóctona. Los protagonistas de la discusión fueron el artista costarricense Enrique Echandi Montero (1866-1959) en relación con la pintura del español Tomás Povedano de Arcos (1847-1943).

Para problematizar la querella visual se alude al concepto de $o$ tredad ${ }^{1}$.El término ha sido propuesto por la antropología y la filosofía como el reconocimiento del otro. Dicho lo anterior, la otredad es concebida como el estudio de la diferencia ligado al orden simbólico y al lenguaje. Así, lo cultural e identitario son aristas del devenir simbolizado (representado) por ambos artistas en interacción con sus valores culturales, identitarios e imaginarios.

Se concibe la otredad autóctona como la manifestación visual del costarricense. Por su parte, el concepto de otredad idealizada se refiere a la percepción del artista foráneo, quien pintó la paisajística y la vida cotidiana del costarricense bajo un afán exótico impropio del escenario costarricense. Precisamente, la primera sección del artículo contextualiza el proceder ideológico y político del conflicto Echandi vs. Povedano a la luz de una propuesta iconográfica y poscolonial.

El segundo apartado discute el aporte de Enrique Echandi en pro de una imagen costarricense. Se toman en consideración las obras plásticas "Ana María Montero" (1902) y “La quema del mesón” (1896) desde un punto de vista iconográfico ${ }^{2}$ y en correlación a la propuesta teórica de Francisco Victoria (1975) y Sepúlveda (1986). Se introduce el concepto encomienda visual ${ }^{3}$ para relacionar la obra del artista con el discurso poscolonial ${ }^{4}$.

El tercer apartado retoma las siguientes obras de Tomás Povedano de Arcos "Novia campesina" (1918) en correspondencia a la construcción de una idealización 
femínea y "Domingüeando" (1915) al lado de la cotidianidad costarricense. Se parte de la propuesta de O’ Gormann (1958) bajo el argumento “América una tierra para poblar"5 y la visión de Dussel (2000) acerca de la instalación de un proyecto transmoderno ${ }^{6}$. De tal forma, al relacionar las propuestas de los teóricos con las intenciones de Povedano se impone un discurso hegemónico y europeizante, empero, el artista Enrique Echandi luchó por la reivindicación de la representación vernácula. El último apartado puntualiza en una reflexión sobre el conflicto visual de finales del siglo XIX y principios del siglo XX desde una perspectiva poscolonial.

\section{El conflicto de identidad nacional en las artes visuales costarricenses a mediados del siglo XIX e inicios del siglo $\mathrm{XX}$}

Después de la Campaña Nacional de 1856, el costarricense exige la independencia y soberanía territorial ante la amenaza del filibustero. El impulso democrático se afianzó con la sustitución del Jefe de Estado a Presidente de la República, este proceder trajo como consecuencia la producción iconográfica cívica como afirmación nacional.

Justamente, José María Castro Madriz y su esposa Pacífica Fernández fundan un ideario cívico que consistió en la elaboración del pabellón de Costa Rica y el Escudo Nacional.

No obstante, Madrizy Fernández se contradicen en la iconografía civil costarricense, puesto que no toman como referentes aspectos identitarios del ser costarricense, sino que se inclinan por la copia de los emblemas franceses. Es decir, retoman los colores de la bandera francesa de forma horizontal y una doble banda de color rojo y blanco. Así, los símbolos patrios a nivel internacional fueron el indicio del conflicto iconográfico que confrontan las artes visuales costarricenses; puesto que la creación de un sistema de signos aborda la necesidad de difundir y crear un motivo cultural para la identificación internacional de la nación costarricense. 
De la otredad autóctona a la otredad idealizada...

Igualmente, hacia 1870 se da la apertura de la primera escuela de arte en la ciudad de San José. Según Montero (1996-1997) “algunos pintores extranjeros se establecieron en el país e intentaron crear escuelas de arte. Todos los intentos fracasaron, porque no había suficientes discípulos para hacer rentable el negocio" (p. 38). El supuesto fracaso de las lecciones de dibujo y pintura en el público costarricense, no se debió a un asunto de carencia vocacional; por el contrario, los jóvenes se vieron interesados en estas áreas.

Una de las contrariedades que enfatiza Montero (1996-1997) fue considerar el arte como una materia de "adorno" en los planes de estudio y que los jóvenes deberían interesasen en estudiar carreras que la sociedad demanda permanentemente como el derecho, la ingeniería o la medicina. A pesar de la condena social hacia el estudio artístico, en la que persiste un correlativo platónico, puesal pintor nacional se le expulsó de unapolis (ciudad) y se fomentóuna condena a quienes se atrevieron a cruzar la trinchera entre la realidad (empleo) versus el talento (ideal); hay quienes persistieron en una educación cuya base fue el arte. Uno de los precursores de este cambio fue Enrique Echandi Montero, quien nace el 17 de febrero de 1866. Desde su infancia se interesó por las artes visuales de manera autodidacta. Años más tarde se incorporó al Liceo de Costa Rica. Al inicio, Echandi, se inclinó por el dibujo con la limitante formativa, pues los educadores extranjeros ofrecían lecciones de carácter manual y carente de refinamiento técnico.

Enrique Echandi luchó por incorporarse a las artes visuales, y un aspecto relevante de su grafía fue la apreciación del retrato antes que el paisaje. Empero, esta determinación hacia tal género artístico se convirtió en una dura meta de reconocimiento público. La inmigración de artistas extranjeros (principalmente españoles, franceses e ingleses) hizo que estos monopolizaran el género artístico (primordialmente el retratístico) y menguaran a los artistas nacionales. De hecho, los galardonados en concursos internacionales siempre fueron foráneos, dado a que se dudó de la capacidad costarricense para figurar. Precisamente, Ferrero (2004) señala:

El maestro Etheridge no permite que sus dos mejores alumnos (Enrique Echandi y Ezequiel Jiménez Rojas) participen, aunque "reconocía su preparación”- tal me confesó Enrique Echandi. Además, Echandi ya había partido para Alemania con el propósito de estudiar pintura (p.75). 
Se creó una brecha entre el iniciado (artista extranjero) y el inexperto (artista nacional) cuya limitación fue la praxis artística (reglas del canon europeo). A nivel internacional (a finales del siglo XIX) los artistas representativos en exposiciones o salones de prestigio fueron los "grandes maestros europeos". Además, el extranjero limitó al artista costarricense por medio del sistema pedagógico. También, el paisaje (un género secundario según las pautas del contexto histórico en la pintura europea) fue una temática impuesta para el costarricense; mientras se le niega, la confección retratista como género de primer orden.

El artista costarricense tuvo que luchar y fomentar las artes visuales a partir de sus propios recursos, dado a que siempre sería considerado un eterno aprendiz. Enrique Echandi decidió formarse para confrontar la supuesta restricción artística costarricense; además que al tener interés por el retrato debía de pugnar el reconocimiento de su talento. A pesar de eso,

Habló de sus ilusiones por efectuar tales estudios y poder fundar una Academia en el país, en donde los jóvenes con inquietudes y capacidades artísticas tuvieran acogida y pudieran practicar y aprender las diferentes técnicas. Se enseñaría dibujo, pintura, escultura y música, y además se darían conciertos y se harían exposiciones (Fournier, 1960, p.8).

Al mismo tiempo, Enrique Echandi viajó a Múnich (Alemania) para cursar estudios profesionales en las artes visuales. Su esperanza era volver al país para ser el director de la Escuela Nacional de Bellas Artes que se pretendía inaugurar tras el fomento nacionalista por parte de la República Costarricense. A la vez, mencionado puesto público había sido prometido por el presidente Rafael Iglesias Castro. Echandi estudió en la ciudad alemana dibujo y óleo, también realizó estudios de francés, alemán, guitarra, piano y composición principalmente sobre Bach y Wagner. Contrajo matrimonio con Elsa Katalina Muukisch Von Hassel, quien le inculcó la música ${ }^{7}$ como otra rama artística poco valorada en Costa Rica.

Pero, el presidente Rafael Iglesias Castro tomó una decisión apresurada respecto a la inauguración y directriz de la Escuela Nacional de Bellas Artes de Costa Rica (1897). A sabiendas de que Enrique Echandi Montero se encontraba fuera del país, Iglesias decidió contratar a un artista español como el director de la institución. Se trató de Tomás Povedano de Arcos, quien aprovechó la oportunidad brindada por Rafael Iglesias Castro. Precisamente, el artista español se asienta nuevamente en la 
construcción de la identidad nacional. No basto el drástico periodo de colonización del siglo anterior, esta vez, es llamado por el propio costarricense para asesoría cultural.

La experiencia adquirida en la formación artística española y sus relaciones sociales consolidaron la dirección de Povedano en la Escuela Nacional de Bellas Artes de Costa Rica (1897). De tal forma, las artes visuales de nuestro país incentivaron la línea tradicional del arte Occidental. Tomás Povedano introdujo el Método Julien, el cual consiste en la copia directa de las obras de arte grecorromanas, motivos naturales como flores, y ornamentación barroca. Por otra parte, este método enfatiza en la necesidad de mantener el realismo y la belleza como conceptos canónicos ${ }^{8}$ en la pintura tradicional.

Al prevalecer una apreciación por el artista extranjero, se creó lo que Roberto Brenes Mesén denominó como una conspiración del silencio. Precisamente, lo que marcó la identidad costarricense no fue su carácter autónomo, ni propio, fue la exaltación e idealización de los goces europeos.

En esta tierra [Costa Rica] es un héroe el artista que no se muere de asfixia; no hay medio ambiente. Nadie estimula a nadie; los ignaros manejan la crítica de arte y un cronista insignificante llega a hacerse el árbitro de la reputación de los hombres de valer. Los literatos callejeros son los que se hacen ruido a sí mismos para embriagarse con un renombre lugareño que se vende y se compra en los salones de un restauran [sic]. No obstante, los literatos y músicas tienen aquí condiciones de vida: las obras maestras de la literatura y de la música pueden llegarnos. A quién hay que compadecer es al pintor. Sin escuela, sin que exista una colección de copias, sin crítica idónea porque los únicos que entienden por lo regular del oficio no escriben; sin público adecuado, el artista por más talento que posea queda reducido a sus solas fuerzas y se ve compelido a vivir en la sombra o a sucumbir (1897, p.2).

La valoración de una formación artística por parte del artista foráneo, no se limitó a la enseñanza, sino que se menguó al artista nacional como gestor cultural en la dirección de la Escuela. Esta reacción provocó que el artífice nacional se viera menguado e inclusive marginado en escala social y persistiera un otro idealizado frente a una otredad autóctona que luchó por su reconocimiento. Es fundamental recalcar que la cimentación de estos términos, devienen de un proceder de la mirada, una mirada impuesta, ideológica, heredada, pedagógica y colonizada tras la apertura y el fomento de las artes visuales en Costa Rica. 


\section{La otredad autóctona desde la perspectiva artística de Enrique Echandi Montero}

Con la introducción de la academia artística europea y la renovación de un sistema político moderno se dio la concepción de una Costa Rica occidentalizada. Asimismo, esta idea se pregonó con la apertura del ferrocarril, el colón como moneda na-cional y la exhortación de deleites parisinos como la importación de un Teatro Nacional (1897).

Justamente, se creó la idealización impropia de la urbe, las vivencias y la vida cotidiana en el imaginario colectivo costarricense.

En consecuencia, persistió una dominación europea en términos simbólicos y el escenario de las artes visuales costarricenses de finales del siglo XIX e inicios del siglo XX continuó atado iconográficamente al modelo de imposiciónartístico español. Desde esta perspectiva, en las artes visuales costarricenses persistió un tipo de encomienda visual, esta vez, ya no bajo prácticas religiosas, sino bajo estructuras artísticas. Mires (1986) define la "encomienda" como "las relaciones de producción que se establecen entre conquistador y conquistado. Su característica esencial reside en la apropiación que el primero efectúa respecto al segundo" ( $\mathrm{p}$. 78). Si bien es cierto, que la encomienda no es una propiedad, implicó un proceso violento de imposición frente al endeble, fue un saqueo sobre la vida social del otro y la posibilidad de generar un control y cuidado (en este caso hacia el artista nacional).

Es fundamental recalcar que los artistas foráneos que visitaron el país no eran grandes artífices, pues eran pintores que proyectaron en América la construcción de su éxito. En consecuencia, tal exacerbación a sus capacidades no es más que un a priori idealizado de la mente costarricense, donde lo extranjero fue siempre sinónimo de gratitud y admiración.

Además, el artista español se asemejó a un encomendero de 1525, dado a que se apropió de las artes visuales y el espacio costarricense para su fomento. A pesar de que la idea inicial era instruir al artista nacional (desde un punto de 
De la otredad autóctona a la otredad idealizada...

vista pedagógico), el proceso se convirtió en un disfraz, un disciplinamiento al desconocido, y que lo aprendido por «el gran maestro» sería un nuevo espacio de valoración artística que opacó las secuelas de la supuesta analfabetización artística.

Por consiguiente, el proceso que recalca Francisco de Victoria (1975) en Reelecciones sobre los indios se convierte en un acercamiento al contexto costarricense, pues se implantó una cuota de adiestramiento como proceso evangelizador - un tipo de misión artística-. Fue como si el artista costarricense tuviese "un derecho a ser convertido" y se justificó un derecho de intervención (ser custodiado visualmente como un iletrado).

Al igual que el proceso evangelizador, al artista costarricense le tocó que seguir las directrices europeas. Por ejemplo, Francisco de Victoria (1975) enfatiza que el colonizado estaba obligado a escuchar y reflexionar por sus errores como proceso de reafirmación religiosa (p.76-77). Esta intervención,se ejemplificó también en las artes visuales, pues la idea de experto-inexperto más que una relación de maestrodiscípulo fue un instrumento de poder y control sobre el artista nacional.

No obstante, la obra del artista nacional Enrique Echandi no cedió al invasor español, no copió los pilares de una academia desgastada ya para el europeo. Si bien es cierto que acudió a una educación foránea, Echandi produjo su propia grafía sin olvidar la raíz costarricense. De hecho, el surgimiento del otro autóctono se convirtió en la amenaza para el otro idealizado ya que desafió y apuntó a un reconocimiento de su diferencia.

En ese sentido, es fundamental señalar, que pese a recibir pocos encargos públicos y al no ser considerado como director de la Escuela Nacional de Bellas Artes, tuvo la aceptación en el medio, razón por la cual pintó un buen número de retratos depersonajes importantes del país.

Dicho de otra manera, el reconocimiento que promovió Enrique Echandi se análoga a la propuesta de Dussel, al enfatizar que se puede llevar a cabo un posicionamiento de lo propio, sin la idea de un mito civilizatorio (se comprende como una acción justa y derecho de intervención para garantizar el porvenir de los pueblos latinoamericanos que encubrió el otro "europeo"), a la vez, de brindar un reconocimiento a la emancipación del otro. Así: 
Para ello, la "otra-cara" negada y "víctima inocente" del sacrificio ritual, que al descubrirse como inocente juzga a la "Modernidad" como culpable, permite "des-cubrir" por primera vez la "otra cara" y esencial a la "Modernidad": el mundo periférico colonial, el indio sacrificado, el negro esclavizado la mujer oprimida, el niño y la cultura popular alineadas, etcétera (las víctimas de la "Modernidad") como víctimas de un acto irracional (como contradicción del ideal racional de la misma Modernidad) (Dussel. 2000, p.49).

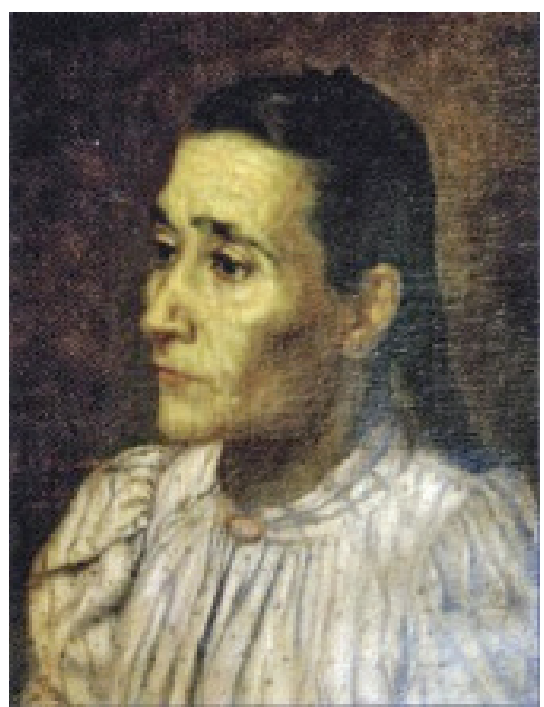

Figura 1. Enrique Echandi. 1904. Ana Montero Aguilar. Óleo sobre tela

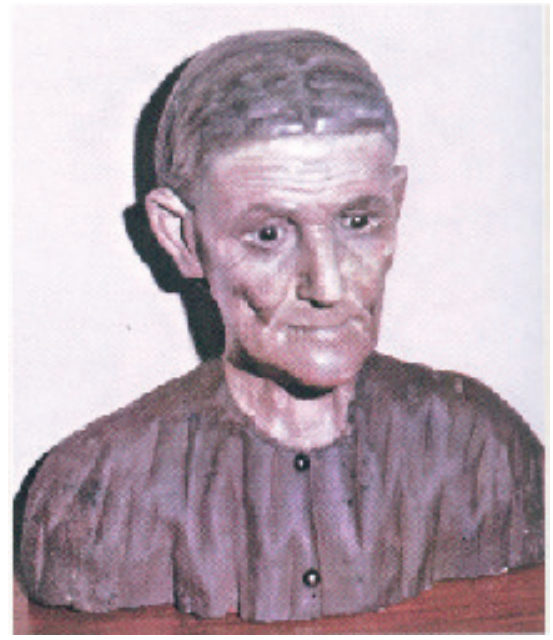

Figura 2. Juan Mora González. Sin fecha.Petronila. Madera Policromada (talla). Museo Nacional de Costa Rica
Enrique Echandi fue el otro autóctono que se manifestó por convicción propia y en defensa de su posición artística, puesto que canaliza la psicología del retratado por medio del folclore costarricense; por ejemplo, la actitud pacífica y humilde de la obra Ana María Montero (Ver figura 1). Asimismo, es interesante como este aspecto fue también canalizado en la obra del imaginero Juan Mora González (1860- 1905) y la obra "Petronila"(Ver figura 2). Al comparar la escultura y la pinturapersiste una concordancia gráfica, pues ambas obras interactúan como apuntes inacabados de la madre costarricense. Igualmente, Montero (2015) destaca que "don Enrique nos ha dejado un estilo más cálido, más basado en el claroscuro; el retrato de su madre Ana Montero Aguilar (1904) "es la encarnación de la matrona costarricense, una dulce melancolía inunda la mirada de la modelo pintada el año de su muerte" (p. 22). La esencialidad de la visión vernácula de la mujer costarricense fue pintada por el artista bajo un sentir humanitario e identificado con la cotidianidad femínea. 
De la otredad autóctona a la otredad idealizada...

De ahí que, la obra de Echandi demuestra la capacidad del costarricense en sobresalir en las artes visuales. La concepción de intervención por parte del europeo implicó un proceso de extensión a la conquista europea como legitimidad cristiana. Por consiguiente, una "causa justa" para la colonización fue la reconciliación con un demiurgo que se olvidó de una América ilegitima, de la cual a su inicio pide la redención de su cultura idolatra y que en palabras de Ginés de Sepúlveda fue necesario confrontar una guerra para su naturalización, es decir, su reconocimiento. El clérigo señala en el Tratado sobre las justas causas de la guerra (1986) lo siguiente:

Con gran razón, por tanto, y con excelente y natural derecho pueden estos bárbaros ser compelidos á [sic] someterse al imperio de los cristianos, siempre que esto pueda hacerse sin gran pérdida de los cristianos mismos, como se puede en este caso en que son tan superiores en las armas. Y sometidos así los infieles habrán de abstenerse de sus nefandos crímenes, y con el trato de los cristianos y con sus justas, pías y religiosas advertencias, volverán á [sic] probidad de las costumbres, y recibirán gustosos la verdadera religión con inmenso beneficio suyo, que los llevará á [sic] la salvación eterna (Sepúlveda, p.132-133).

Es primordial destacar que la obra de Enrique Echandi sembró un discurso de ruptura $^{9}$ ante la hegemonía representativa europea, y desde luego, en discrepancia con disertacionescoloniales como las de Sepúlveda. No obstante, dichas roturas con elementos autónomos no fueron canalizados de forma tan asertiva en la recepción social costarricense (dado a la fijación del discurso académico dictado por Povedano). Un ejemplo fue el acogimiento nacional de la obra titulada $L a$ quema del mesón (1896) (Ver Figura 3).

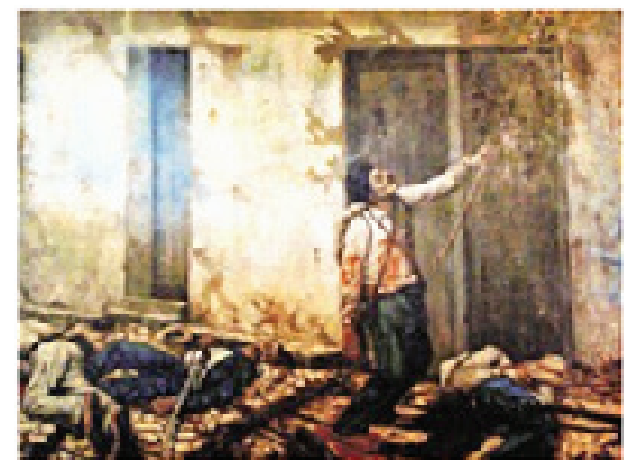

Figura 3. Enrique Echandi. 1986. La quema del mesón. Óleo sobre tela 
El héroe representado no se ajustó al gusto europeizante de la obra de Aristide Croisy $^{10}$ (Ver figura 4) ya que pintó al héroe en una posición débil, propiamente capturó el momento en que Juan Santamaría entregó su vida.

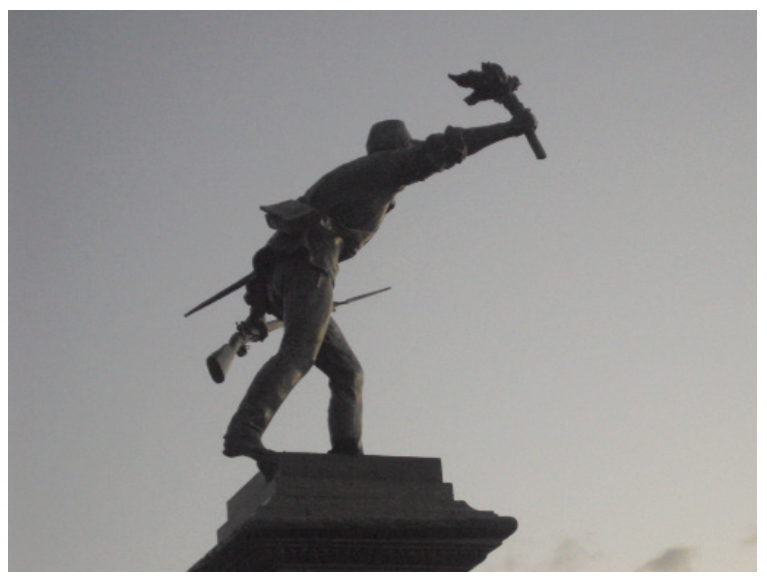

Figura 4. Aristide Croisy (escultor) Durenne (fundidor). Estatua de Juan Santamaría. 1890. Parque Juan Santamaría, Alajuela. Fotografia: Andrea Calvo Díaz, 2012

Es decir, el pintor nacional articuló un discurso visual original y conllevó un relato histórico que capturó la humanidad del momento. Empero, como enfatiza Molina (2005) en Costarricense por dicha: identidad nacional y cambio cultural en Costa Rica durante los siglos XIX y XX:

El impacto de esa descalificación afectó adversariamente la carrera de Echandi, que quedó al margen de los círculos oficiales, al tiempo que fortaleció la orientación que el pintor español, Tomás Povedano de Arcos, le imprimió a la Escuela de Bellas Artes (p.56).

La carga social de un sujeto carente llevó al costarricense a suplantar su conciencia identitaria, y a valorar "lo de afuera" como la resonancia de una conquista vigente. Sin embargo, el papel de Enrique Echandipromovió la lucha constante por reivindicar el carácter autóctono de la cultura costarricense. 


\section{La otredad idealizada desde la visión artística de Tomás Povedano de Arcos}

O'Gormann enfatiza en su texto La invención de América: el universalismo de la cultura de Occidente (1958) la idea de una América como un continente para poblar, es decir, invadir con propiedad y derecho. La denominación de una tierra anulada, extraña y vacía acarrea la obligación europea de una administración y adiestramiento del indígena. El europeo se basa en la concepción histórica como recurso memorioso de apropiación.

Así, “América se presenta como el continente ignoto, como la parte extraña del mundo como algo novedoso, de suerte que, si en el plano geográfico se le reconoce una identidad como "parte", en la esfera del acontecer histórico es un ente del que es preciso dar razón" (O’Gormann, 1958, p. 82). Precisamente, este “dar razón” fue la causa fundamental de muchas inmigraciones europeas al continente americano, pues tenían la imagen de porvenir, a la vez, de instaurar un discurso poscolonial.

La inmigración europea repercutió en las artes visuales, no solo en el contexto costarricense, sino en el latinoamericano. Muchos de los artistas occidentales, al igual que en el proceso colonial, se trasladaron a América con la idea un progreso y alcance social que no obtuvieron en Europa.

Tomás Povedano de Arcos perteneció a ese grupo de jóvenes europeos que vieron en América la idea de progreso y difundió la idea de superioridad por ser hijo de un contexto histórico con reconocimiento y legitimidad (por ejemplo, estudios en arte). Al mismo tiempo, se recurrió al español como el pedagogo ilustrado y el maestro incuestionable.

Según Ricardo Ulloa (1982) Povedano colaboró en el movimiento político ecuatoriano al promover el establecimiento de la Primera República; asimismo, se le notificó el triunfo para delegar la Escuela de Dibujo en Cuenca en Guayaquil Ecuador (p.37). Sin embargo, tiempo después fue contratado por Rafael Iglesias Castro para delegar la Escuela Nacional de Bellas Artes en Costa Rica. Su procederpedagógico se destacó por la utilización del Método Julien ${ }^{11}$, el cual introduce en la formación artística costarricense. Dicho método implicó un 
disciplinamiento que en términos Foucaultianosinvolucró un dispositivo de control y una forma estratégica por medio de la autoridad y la obediencia, así Occidente complicó "esa suerte de pequeña porción del mundo cuyo extraño y violento destino fue imponer finalmente sus maneras de ver, pensar, decir y hacer al mundo entero" (Foucault, 2012, p. 31).

Dicho lo anterior, el proceder del extranjero fue transgresor, a la vez, aludió a la inferioridady a la barbarie de quién debe disciplinar. Así pues, la idea de expansión territorial se vuelve en desahogo artístico, por ello, la promoción de las escuelas de arte en su mayoría fueuna prerrogativa consumidapor el mismo europeo.

En este caso se crea un ideal modernista en el contexto de las artes visuales costarricenses, y cabe señalar que este ideario proviene de un imaginario europeo, donde se destacó una oportunidad de realización profesional, a partir del canon artístico clásico Occidental. Al respecto Cuevas (2000) señala: "La escogencia de Povedano como director de la Escuela frente a otros pintores nacionales, especialmente, Enrique Echandi, muestra a claras las preferencias por lo extranjero de la élite gobernante" (p. 457).

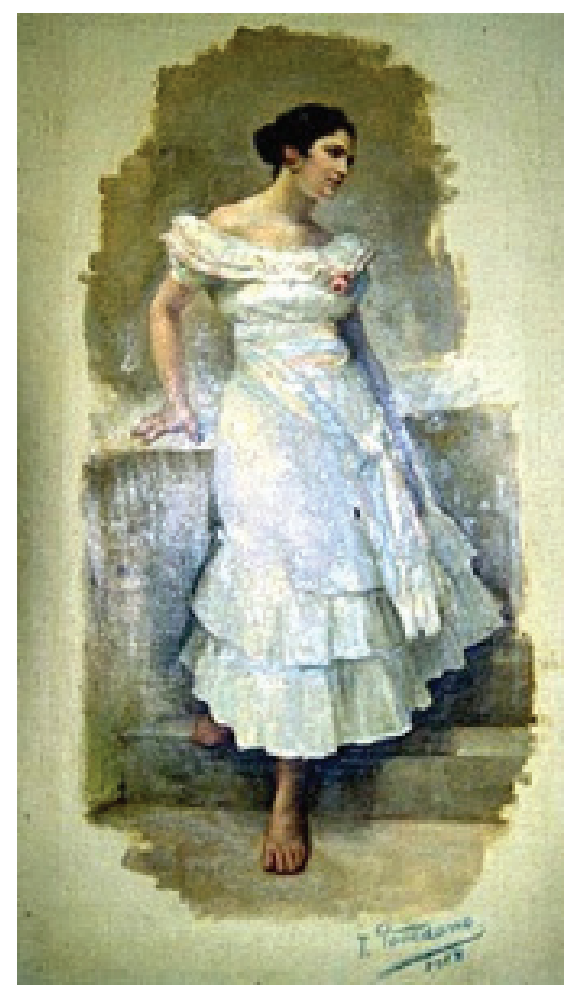

Figura 5. Tomás Povedano de Arcos. 1918. Novia Campesina. Óleo sobre tela

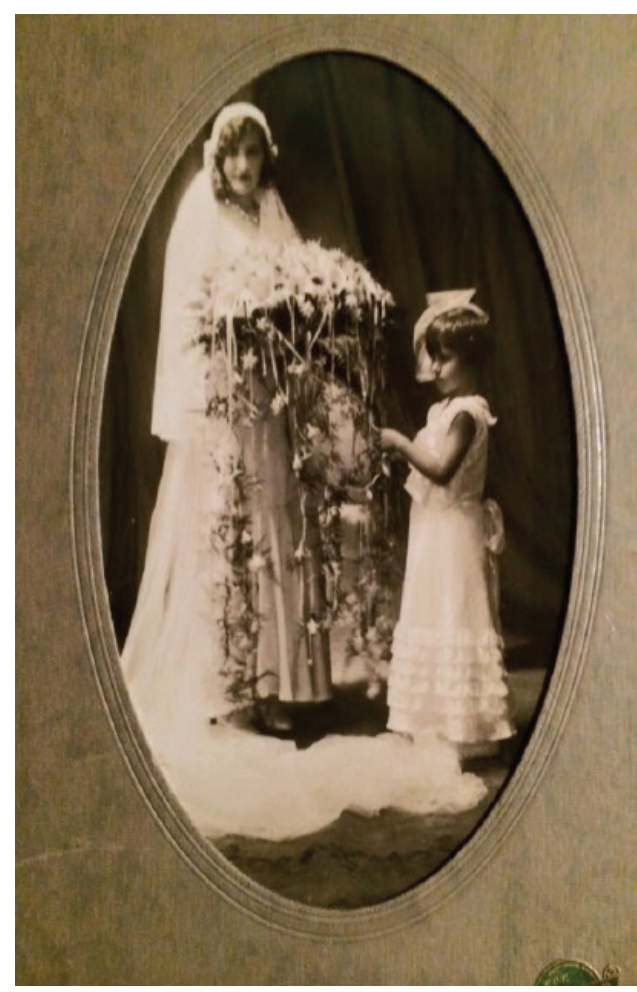

Figura 6. Fotografía de Isabel Alvarado Peralta y a niña María Eugenia Domián con su vestido de novia. 1932. Propiedad de Arnaldo Moya Gutiérrez 
De la otredad autóctona a la otredad idealizada...

A nivel artístico la obra de Tomás Povedano de Arcos fue la continuación disciplinaria de un modelo de exigencia; de ahí que, el otro imaginado (artista costarricense) fue secundario hasta el punto de quebrantar la esfera cultural e identitaria costarricense. Sirva de ejemplo, la obra "novia campesina" (1918) (Ver figura 5) el cual alude a la representación femenina que no corresponde con el contexto socioculturalcostarricense por varias razones; la primera deviene del atavío indumentario que ejerce sensualismo. Justamente, la mujer se presenta como un objeto erótico que utiliza su belleza comoatracción sexual; aspecto que no coincidió con la sociedad conservadora costarricense, pues como señala Fischel (1992):

La prolongada subordinación de la mujer en la sociedad adquirió connotaciones especiales bajo el esquema liberal. Desde la época colonial, se tenía la percepción de que la mujer había sido creada para obedecer en todos los estadios de su vida: primero a su padre, luego a su esposo y más tarde a sus hijos. Al mismo tiempo se proclamaba que sus mejores virtudes eran la timidez, la religiosidad, la modestia y la ternura, así como los modales discretos (p. 57).

A pesar de que la mujer era considerada un objeto de complacencia, entre sus características prevaleció la sumisión, el apocamiento y el recato. Por consiguiente, la representación de "novia campesina" no se adecuó al prototipo de mujer costarricense a inicios del siglo XX, puesto que la posición de la mujer muestra sensualidad y se ubicó en un escenario de espera; por su parte, el vestuario no atañe a la indumentaria usual de la costarricense, el cual fue un atavío blanco y sumamente mesurado. En ese caso, el óleo sobre tela exportó el paradigma europeo y se ajustó a los vestuarios autóctonos de Andalucía (España) de donde procedía el artista.

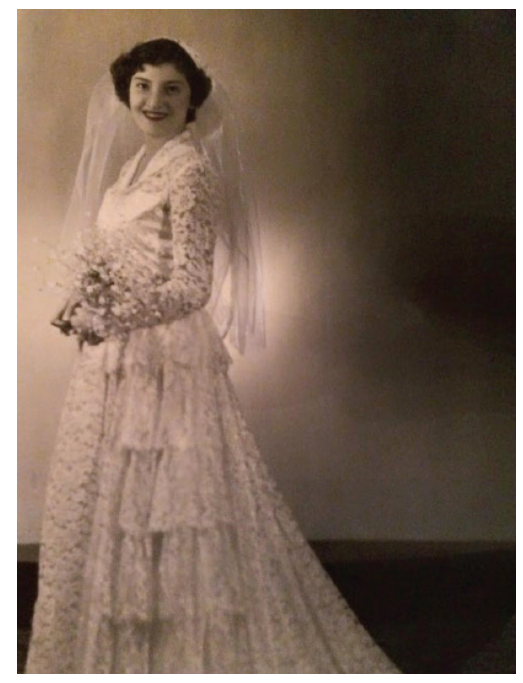

Figura 7. Fotografía de Mayra Gutiérrez Alvarado con su vestido de novia. 1952. Propiedad de Arnaldo Moya Gutiérrez 
Ahora bien, al confrontarla obra "novia campesina" con una fotografía de la década de los años treinta correspondiente a Isabel Alvarado Peralta (Ver figura 6) y otra fotografía de la década de los cincuentas de Mayra Gutiérrez Alvarado (Ver figura 7) se constata que el proceder indumentario del ideal costarricense era sutil, conservador y pulcro aunado al concepto de los valores religiosos y familiares de una mujer decorosa, el cual demuestra que el ideal femíneo de sumisión hogareña rigió por mucho tiempo en la primera parte del siglo XX empleando como forma de control: la vestimenta ${ }^{12}$.

Con respecto al ropaje es fundamental señalar que el costarricense promulgó un parentesco con los ideales europeos. Además, como destaca Jiménez (2002) elaboró una invención de una Costa Rica blanca como invención nacionalista, así:

En el discurso liberal de blanqueamiento hay estrategias sutiles como la de reconocer y borrar el mestizaje en un mismo movimiento. Este era un reconocimiento tramposo pues se utilizó para negarla existencia de la población indígena.En este sentido, el reconocimiento de la población costarricense como población mestiza significaba la disolución discursiva de los grupos indígenas. Además de eso, fue un reconocimiento provisional e intranscendente, pues el mestiza-je aparecía como un proceso con una parte activa y dominante, el varón blanco español, y una parte pasiva, receptiva, y al final insignificante en términos de sangre y cultura: la mujer indígena (p. 180).

En este sentido, la obra de Tomás Povedano de Arcos reafirmó no sólo un proceder poscolonial, sino que revivió los ideales europeos preconcebidos por el costarricense en el proceso de colonización, es decir, la elaboración de un "otro idealizado", un "otro imaginado". En contraste con lo anterior, "Povedano calzó a la perfección con la estética oficial costarricense, que resumía, a su vez, la concepción ideológica de las altas esferas sociales y políticas: la oligarquía cafetalera y la burguesía preferentemente capitalina" (González, p. 222). 


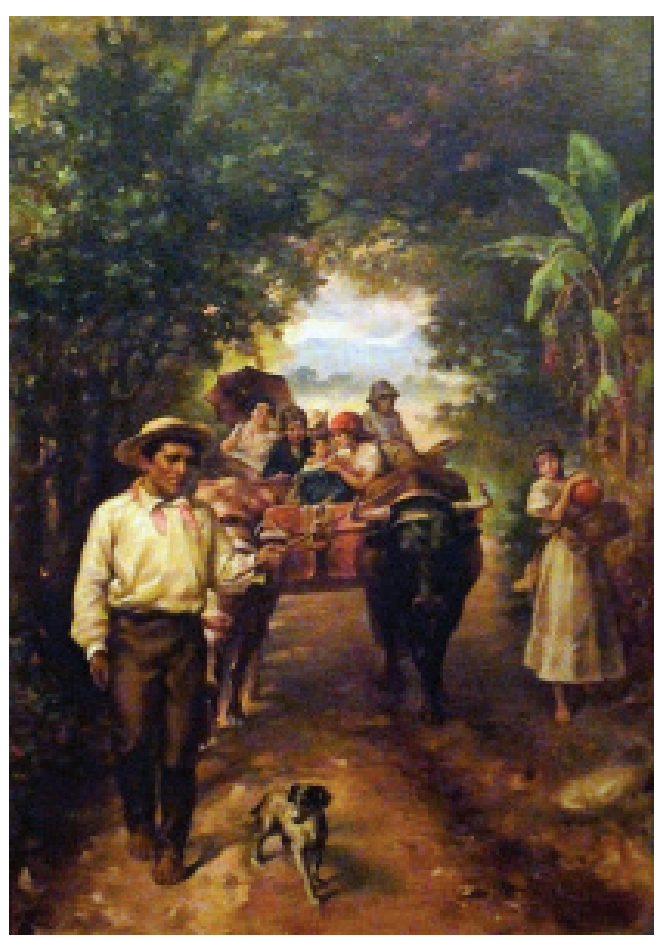

Figura 8. Tomás Povedano de Arcos. 1915. Domingüeando. Óleo sobre tela
En continuidad con esta cimentación del ideal europeo, la obra "Domingüeando" (1915) (Ver figura 8) exaltó una cotidianidad que no correspondió a las vivencias de una familia promedio costarricense. La pintura muestra el paseo de un linaje alto, puesto que las mujeres visten atavíos europeos, se pone por caso, el uso de una sombrilla y la usanza de sombreros veraniegos en las mujeres. Además, se prosigue la representación de una vegetación con ramajes impropios del paisaje montañoso tropical costarricense.

En cierto modo, se puede decir que el proceder academicista de Povedano trató de vincularse con los elementos de la cotidianidad del campesino costarricense, por ejemplo, la representación de la carreta; no obstante, infringió el escenario con atributos occidentales y exageró en la representación de una "Costa Rica blanca”. En palabras de Dussel (2009) se da un desplazamiento semántico del concepto «Europa» como mito civilizatorio, así la emancipación consistió en proyectar una modernidad Occidental, un proceder eurocéntrico $(p, 65)$.

Dicho de otro modo, al tratar la temática vernácula costarricense, Tomás Povedano de Arcos afianzó una estrategia poscolonial y con ello ganócamarería con la clase alta costarricense, a la vez de potencializar el discurso academicista de las artes visuales Occidentales, pues como señala Carlos Echeverría en Historia Crítica del Arte Costarricense: 
Era un pintor de mediano talento que, además, a diferencia de Span, no se interesó particularmente por los temas pictóricos que ofrecía Costa Rica. Hizo muchos retratos y algunos cuadros alegóricos con temas indígenas extraídos posiblemente de su estancia en Ecuador. No dejó discípulos notables. No obstante, a pesar suyo, Povedano jugó un papel importante para los jóvenes artistas de talento que nacieron a principios del siglo: les mostró lo que no había que hacer (1986, p.52).

En consecuencia, el proceder pedagógico instaurado por Tomás Povedano de Arcos respondió a un sistema de obligación avalada por la Cultura Occidental, a la vez, de contribuir con el imaginario blanquecino de las clases altas costarricenses. El artífice español buscó la expansión de su modernidad, en medida que dibujaba un imaginario Occidental en una Costa Rica que buscaba identidad y legitimidad nacional.

\section{Epílogo}

En síntesis, desde el primer acuerdo artístico en la dirección de la Escuela Nacional de Bellas Artes (1897) en Costa Rica se previó un gusto por los cánones europeos, los cuales afianzaron el gusto de la oligarquía cafetalera,simultáneamente, restringió la emancipación artística costarricense. Es decir, se creó una bifurcación de otredades, una en pro de la autonomía costarricense "otredad autónoma" y otra a favor de los ideales occidentales "otredad idealizada".

La decisión de Rafael Iglesias Castro al elegir a Tomás Povedano de Arcos imprimió un proceder poscolonial, y lo inaudito fue la disposición política por parte del costarricense. Por lo tanto, se da un proceso de sustitución simbólica, y como enfatiza Mora (2012):

El periodo colonial centroamericano vio en el otro-indígena un remanente del pasado, un sujeto antihistórico, marcado por la barbarie, el salvajismo y la resistencia "progreso". De esta manera, por ejemplo, el discursode exclusión

y de incivilización. En el caso costarricense, las poblaciones autóctonas son borradas de la memoria y marginas de la dinámica social. La constitución del estado-nación se alimenta de la imagen de una población homogénea y blanca (pp. 167-168). 
A pesar de la exaltación por los goces europeos, es vital señalar que el carácter disruptivo del artista Enrique Echandi ante las decisiones artísticas y políticas en relación con los planteamientos europeos evoca a un periodo histórico de reflexión. De ese modo, es fundamental el reconocimiento del talento nacional, así como la construcción de invenciones artísticas propias, y dejar de lado, el modelo poscolonial que aún en la actualidad continúa presente.

\section{Notas}

1 Se toma en consideración el punto de vista de Tzvetan Todorov (2007) al enfatizar que el descubrimiento del otro debe ser asumido bajo la experiencia social encerrada en dos extremos, "aquel en que el yo invade el mundo, y aquel en que el mundo acaba por absorber al yo, en forma de cadáver o cenizas (p.257). Esta dialéctica se representa en la comprensión del "otro autóctono" y el "otro idealizado" en el proceder sociocultural del contexto artístico costarricense.

2 La iconografía es el estudio de la imagen bajo tres pasos: pre iconográfico, iconográfico e iconológico. La teoría fue planteada por el historiador del arte Erwin Panofsky.

3 La autora utiliza la palabra encomienda visual para referirse al proceso de evangelización y apropiación de la colonia desde una perspectiva visual, es decir, a partir del significado y contexto de la representación iconográfica costarricense.

${ }^{4}$ El discurso poscolonial se refiere a los estudios posteriores de la colonia cuyo proceso tiene implicaciones similares.

5 Entiéndase, América como "un inmenso territorio legítimamente apropiable y explotable en benéfico propio, una nueva e imprevista provincia de la Tierra que el destino tenía reservada a Europa para la prosecución de los supremos fines históricos" (O’Gormann, 1958, p. 89).

${ }^{6}$ Enrique Dussel asume el concepto de transmodernidad como las teorías propias del pensamiento latinoamericano frente al pensamiento Occidental como una forma autónoma de discusión cultural. 
7 La investigadora María Clara Vargas Cullel en el texto De las fanfarrias a las salas de concierto música en Costa Rica (1840-1940) (2004) destaca que entre las principales asociaciones culturales del país se encontraba el grupo Ateneo en el cual la participación de Enrique Echandi fue significativa y promotora de profesionales en el área musical (p. 178).

8 En este período existió en Europa un rompimiento entre el realismo como propuesta académica y el augurio de la modernidad. En este sentido, se dio en nuestro país la instalación del eco realista ya desgastado en Occidente y una descontextualización de los movimientos en decadencia.

9 Si bien es cierto, el artista realizó sus estudios en Alemania su ruptura radicó en la canalización de la cotidianidad y esencialismo costarricense, desde un punto de vista de autonomía y abstracción identitaria; a diferencia de Tomás Povedano de Arcos quién impuso el discurso académico, y al abordar la temática costarricense recurrió al imaginario occidental de la blanquicidad y escenografía europeizante.

${ }^{10}$ Como señala Annie Lemistre Pujol en Dos bronces conmemorativos y una gesta heroica. La estatua de Juan Santamaría y el Monumento Nacional (1988) la efigie del héroe fue confeccionada por Aristide Croisy y encargada por Manuel María Peralta; No obstante, "como se ha conservado la fotografía del modelo en el propio taller del escultor, se puede pensar que Croisy escogió a uno de los jóvenes soldados que ya había trabajado con él para anteriores monumentos" (p. 43). Es decir, la obra que se ubica actualmente en el parque Juan Santamaría procede de las características artísticas del contexto francés y carece del aurea vernácula del relato histórico costarricense.

${ }^{11}$ Consiste en un método de aprendizaje artístico, el cual supone tres o cuatro procedimientos: "primero algunos ejes de dirección, luego un encajado general para ubicar y proporcionar la forma en el papel, posteriormente un delineo más preciso del encaje y de los espacios negativos, así como el recurso de líneas paralelas para representar sombras o modelado y finalmente, una copia medianamente detallada" (Sánchez, 2013, p. 5).

${ }^{12}$ Según Lipovetsky (1996) "Con la moda empieza el poder social de los signos ínfimos, el asombroso dispositivo de distinción social otorgado al uso de los nuevos modelos" (p. 33), aspecto relevante en la elaboración nacionalista costarricense y representado por la oligarquía cafetalera. 
De la otredad autóctona a la otredad idealizada...

\section{Referencias}

Botey, A. (Coordinadora). (2000). Costa Rica: Estado, Economía, Sociedad y Cultura desde las sociedades autóctonas hasta 1914. San José: Editorial de la Universidad de Costa Rica.

Brenes, R. (1897, 18 de marzo). "La Nueva Escuela”. E1 Fígaro, p.2.

Cabrera, R. (1996). La quema del mesón. Foro: pintura centenaria del artista Enrique Echandi. Alajuela: Museo Histórico Juan Santamaría.

Echeverría, C. (1986). Historia crítica del arte costarricense. San José: EUNED.

Ferrero, L. (2004). Sociedad y Arte. San José: EUNED.

Dussel, E. (2000). "Europa, modernidad y eurocentrismo", en Colonialidad del saber eurocentrismo y ciencias sociales. Perspectivas Latinoamericanas. Edgardo Lander (Editor), Caracas, IESALC.

Fischel, A. (1992). El uso ingenioso de la ideología en Costa Rica. San José: EUNED.

Foucault, M. (2012). El poder una bestia magnifica sobre el poder, la prisión y la vida. (Traducción Horacio Pons) por Buenos Aires: Siglo Veintiuno Editores.

Fournier, C. (1960). Datos para una biografía y semblanza de don Enrique Echandi M. Tesis para optar por el grado de Licenciatura. Universidad de Costa Rica.

González, A. (2007). Historia General del Arte. Tomo 2. San José: Editorial de la Universidad de Costa Rica.

Jiménez, A. (2002). El imposible país de los filósofos. El discurso filosófico y la invención de Costa Rica. San José: Ediciones Perro Azul. 
Lemistre, A. (1988). Dos bronces conmemorativos y una gesta heroica. La estatua de Juan Santamaría y el Monumento Nacional. Alajuela: Museo Histórico Cultural Juan Santamaría.

Lipovetsky, G. (1996). El imperio de efimero. La moda y su destino en las sociedades modernas. (Traducción Felipe Fernández y Carmen López). Barcelona: Editorial Anagrama.

Mires, F. (1986). En nombre de la cruz: discusiones teológicas frente al holocausto de los indios: periodo de conquista.Madrid: Alianza Editorial.

Molina, I. (2005). Costarricense por dicha: identidad nacional y cambio cultural en Costa Rica durante los siglos XIX y XX. San José: Editorial de la Universidad de Costa Rica.

Montero, C. (2015). Arte Costarricense: 1897-1971. San José: Editorial de la Universidad de Costa Rica.

(1996-1997). Centenario. Herencia. Vol.8, n² - Vol.9 n¹, p. $35-40$.

Mora, L. (2012). La conquista interminable: reflexiones poscoloniales sobre la alteridad. Revista Estudios. No 25, p. 155-174.

O'Gorman, E. (1958). La invención de América: el universalismo de la cultura de Occidente. México: Fondo de Cultura Económica.

Sánchez, J. (2013). Las láminas de dibujo de Escuela Nacional de Bellas Artes. Revista Humanidades. Vol. 3, p. 1-10.

Sepúlveda, G. (1986). Tratado sobre las justas causas de la guerra. Madrid:FCE.

Todorov, T. (2007). La conquista de América. (Traducción de Flora Botton Burlá). Madrid: Siglo Veintiuno Editores. 
Vargas, M. (2004). De las fanfarrias a las salas de concierto música en Costa Rica (1840-1940). San Pedro de Montes de Oca: Editorial de la Universidad de Costa Rica.

Ulloa, R. (1982). Pintores de Costa Rica. Costa Rica: Editorial de Costa Rica. 